\title{
APPENDIX
}

Table A-1

Estimated effects of speed camera program on mean speeds based on linear regression model

\begin{tabular}{lrrrr}
\hline & & & Estimat & Percent \\
Effect & F-value & p-value & e & change \\
\hline & 2436. & & & \\
Site & 94 & $<0.0001$ & & \\
& 547.6 & & & \\
Time (2014 vs. 2006) & 5 & $<0.0001$ & -0.0421 & -4.1 \\
Vehicles per hour (per 10 vehicles) & 26.01 & $<0.0001$ & -0.0003 & -0.03 \\
Camera sites vs. control sites in & 3131. & & & \\
2014 & 98 & $<0.0001$ & -0.1075 & -10.2 \\
\hline
\end{tabular}

\section{Table A-2}

Logistic regression results of effects of speed cameras on likelihood that vehicles exceeded posted speed limits by more than $10 \mathrm{mph}$

\section{Percent \\ change \\ in}

Wald

Odds likelihoo

Effect

Chi-square

p-value

Estimate

ratio

d 
Site

Time (2014 vs. 2006)

Vehicles per hour (per 10

vehicles)

Camera sites vs. control sites in
$11450.26<0.0001$

$130.74<0.0001 \quad-0.5003 \quad 0.61$

$\begin{array}{llll}58.86 & <0.0001 & -0.0107 & 0.99\end{array}$

$-62$

$\begin{array}{llll}562.14 & <0.0001 & -1.0618 & 0.35\end{array}$

$562.14<0.0001-1.0618<0.35$




\section{Table A-3}

Descriptive statistics of variables in the logistic regression models of the likelihood that crash involved incapacitating or fatal injury on camera-eligible roads and on potential spillover roads

\begin{tabular}{|c|c|c|c|c|c|}
\hline \multirow[t]{2}{*}{ Variables } & \multirow[t]{2}{*}{ Description } & \multicolumn{2}{|c|}{$\begin{array}{c}\text { Model for } \\
\text { camera eligible } \\
\text { roads }\end{array}$} & \multicolumn{2}{|c|}{$\begin{array}{c}\text { Model for } \\
\text { potential } \\
\text { spillover roads }\end{array}$} \\
\hline & & Mean & Std dev & Mean & Std dev \\
\hline Crash involving incapacitating or fatal injury & $\begin{array}{l}1 \text { if crash involved such an injury, } 0 \\
\text { otherwise }\end{array}$ & 0.06 & 0.0006 & 0.07 & 0.0014 \\
\hline $\begin{array}{l}\text { First quarter (Jan-Mar) vs. fourth quarter (Oct- } \\
\text { Dec) }\end{array}$ & $\begin{array}{l}1 \text { if crash occurred during first quarter, } 0 \\
\text { otherwise }\end{array}$ & 0.24 & 0.0012 & 0.23 & 0.0023 \\
\hline $\begin{array}{l}\text { Second quarter (Apr-Jun) vs. fourth quarter } \\
\text { (Oct-Dec) }\end{array}$ & $\begin{array}{l}1 \text { if crash occurred during second quarter, } 0 \\
\text { otherwise }\end{array}$ & 0.25 & 0.0012 & 0.24 & 0.0023 \\
\hline $\begin{array}{l}\text { Third quarter (Jul-Sep) vs. fourth quarter (Oct- } \\
\text { Dec) }\end{array}$ & $\begin{array}{l}1 \text { if crash occurred during third quarter, } 0 \\
\text { otherwise }\end{array}$ & 0.24 & 0.0012 & 0.25 & 0.0024 \\
\hline
\end{tabular}


Entire after period (Jun 2007-Dec 2013) vs.

before period (Jan 2004-Apr 2007)

2009 law period (Oct 2009-Dec 2013) vs.

before period (Jan 2004-Apr 2007)

Corridor approach period (Jun 2012-Dec 2013)

vs. before period (Jan 2004-Apr 2007)

Montgomery County vs. Fairfax County

Wet/snowy/icy road vs. dry road

Curve road vs. straight road

Pedestrian involvement

Nighttime (9 p.m. to 6 a.m.) vs. daytime
1 if crash occurred during Jun 2007-Dec

2013, $\quad 0$ otherwise

1 if crash occurred during Oct 2009-Dec

2013, $\quad 0$ otherwise

2013, $\quad 0$ otherwise

1 if crash occurred in Montgomery County,

0 if in Fairfax County

1 if crash occurred on wet/snowy/icy road,

0 if on dry road

1 if crash occurred on curve, 0 if on straight

road

1 if crash involved pedestrian, 0 if no

pedestrian

1 if crash occurred at night, 0 otherwise $\begin{array}{llll}0.37 & 0.0013 & 0.39 & 0.0027\end{array}$

$\begin{array}{llll}0.13 & 0.0009 & 0.14 & 0.0019\end{array}$

$\begin{array}{llll}0.23 & 0.0011 & 0.24 & 0.0024\end{array}$

$\begin{array}{llll}0.14 & 0.0010 & 0.10 & 0.0016\end{array}$

$\begin{array}{llll}0.60 & 0.0013 & 0.63 & 0.0026\end{array}$

$\begin{array}{llll}0.02 & 0.0004 & 0.02 & 0.0007\end{array}$

$\begin{array}{llll}0.17 & 0.0010 & 0.16 & 0.0020\end{array}$ 
Speed limit 30 mph vs. 25 mph

Speed limit 35 mph vs. 25 mph
1 if crash occurred on road with $30 \mathrm{mph}$

speed limit, 0 otherwise

1 if crash occurred on road with $35 \mathrm{mph}$

speed limit, 0 otherwise
$0.16 \quad 0.0010$

$0.56 \quad 0.0013$ 


\section{Table A-4}

Logistic regression results of effects of speed cameras on likelihood that crash involved incapacitating or fatal injury on camera-eligible roads

\begin{tabular}{|c|c|c|c|}
\hline \multirow[b]{2}{*}{ Parameter } & \multicolumn{3}{|c|}{ Standard } \\
\hline & Estimate & error & p-value \\
\hline Intercept & -3.0244 & 0.0406 & $<0.0001$ \\
\hline Number of years (since 2004) & -0.0511 & 0.0145 & 0.0004 \\
\hline First quarter (Jan-Mar) vs. fourth quarter (Oct-Dec) & 0.00889 & 0.0353 & 0.801 \\
\hline Second quarter (Apr-Jun) vs. fourth quarter (Oct- & 0.061 & 0.0336 & 0.0695 \\
\hline \multicolumn{4}{|l|}{ Dec) } \\
\hline Third quarter (Jul-Sep) vs. fourth quarter (Oct-Dec) & 0.1435 & 0.0329 & $<0.0001$ \\
\hline Entire after period (Jun 2007-Dec 2013) vs. before & 0.0149 & 0.0574 & 0.7951 \\
\hline \multicolumn{4}{|l|}{ period (Jan 2004-Apr 2007) } \\
\hline 2009 law period (Oct 2009-Dec 2013) vs. before & -0.036 & 0.0607 & 0.5531 \\
\hline \multicolumn{4}{|l|}{ period (Jan 2004-Apr 2007) } \\
\hline Corridor approach period (Jun 2012-Dec 2013) vs. & 0.1756 & 0.0636 & 0.0057 \\
\hline \multicolumn{4}{|l|}{ before period (Jan 2004-Apr 2007) } \\
\hline Montgomery County vs. Fairfax County & 0.00403 & 0.0355 & 0.9098 \\
\hline Effects of speed cameras & -0.2302 & 0.061 & 0.0002 \\
\hline Effects of 2009 law change over and above speed & 0.0827 & 0.0726 & 0.2547 \\
\hline \multicolumn{4}{|l|}{ cameras } \\
\hline Effects of corridor approach over and above speed & -0.3762 & 0.0906 & $<0.0001$ \\
\hline
\end{tabular}


Wet/snowy/icy road vs. dry road

Curve road vs. straight road

Pedestrian involvement

Nighttime (9 p.m. to 6 a.m.) vs. daytime

Speed limit $30 \mathrm{mph}$ vs. $25 \mathrm{mph}$

Speed limit $35 \mathrm{mph}$ vs. $25 \mathrm{mph}$ $\begin{array}{lll}-0.1599 & 0.0292<0.0001\end{array}$

$0.5385 \quad 0.0302<0.0001$

$2.2954 \quad 0.0406<0.0001$

$0.201<0.0301<0.0001$

$0.2873 \quad 0.0387<0.0001$

$0.335 \quad 0.0285<0.0001$

Note: p-value was based on Wald Chi-Square test.

Table A-5

Logistic regression results of effects of speed cameras on likelihood that crash involved incapacitating or fatal injury on potential spillover roads

Standard

Estimate error p-value

Intercept

$-2.7255$

0.078

$<0.0001$

Number of years (since 2004)

$\begin{array}{lll}-0.0304 & 0.0264 & 0.2491\end{array}$

First quarter (Jan-Mar) vs. fourth quarter (Oct-Dec)

$0.0694 \quad 0.0642 \quad 0.2797$

Second quarter (Apr-Jun) vs. fourth quarter (Oct-

0.0977

0.0615

0.1118 Dec)

Third quarter (Jul-Sep) vs. fourth quarter (Oct-Dec)

$0.1106 \quad 0.0606 \quad 0.0681$

Entire after period (Jun 2007-Dec 2013) vs. before

$\begin{array}{lll}-0.0116 & 0.1302 & 0.9291\end{array}$

period (Jan 2004-Apr 2007) 
2009 law period (Oct 2009-Dec 2013) vs. before

$\begin{array}{lll}-0.1595 & 0.1405 & 0.2562\end{array}$ period (Jan 2004-Apr 2007)

Corridor approach period (Jun 2012-Dec 2013) vs.

$0.1012 \quad 0.1573 \quad 0.5199$ before period (Jan 2004-Apr 2007)

Montgomery County vs. Fairfax County

$0.3326 \quad 0.0735<0.0001$

Effects of speed cameras

$\begin{array}{lll}-0.2017 & 0.1222 & 0.099\end{array}$

Effects of 2009 law change over and above speed

$\begin{array}{lll}0.0633 & 0.1448 \quad 0.6622\end{array}$ cameras

Effects of corridor approach over and above speed

$\begin{array}{lll}-0.191 & 0.1754 & 0.2763\end{array}$ cameras and 2009 law change

Wet/snowy/icy road vs. dry road $\begin{array}{lll}-0.1793 & 0.0519 \quad 0.0006\end{array}$

Curve road vs. straight road

$0.7319 \quad 0.0599<0.0001$

Pedestrian involvement

$2.3743 \quad 0.09 \quad<0.0001$

Nighttime (9 p.m. to 6 a.m.) vs. daytime

$0.0525 \quad 0.0567 \quad 0.3547$

Note: p-value was based on Wald Chi-Square test.

\section{Likelihood That a Crash Was Speeding-related}

Additional logistic regression analyses evaluated the effects of the speed cameras, 2009 law change, and corridor approach on the likelihood that a crash was speeding-related on camera-eligible roads and on potential spillover roads. As in the models of the effects of the speed camera program on the likelihood that a crash involved an incapacitating or fatal injury, the before study period was January 2004-April 2007. With regard to the after study periods, June 2007-December 2013 was the period when speed cameras were used, October 2009December 2013 was the period following the speed camera law change, and June 2012- 
December 2013 was the period when the corridor approach was used. The odds ratios derived from the logistic regression models were transformed into estimates of relative risk.

Speeding-related crashes were defined as those involving at least one driver reported by the police to be exceeding the speed limit or driving too fast for conditions. Separate models examined the camera effects on camera-eligible roads and the camera effects on potential spillover roads. In these models, the dependent variable was a binary crash indicator (crash being speeding-related or not). The independent variables were the number of years since 2004, a quarter of year indicator, time of day indicator (9 p.m-6 a.m. vs. daytime), study period indicators (entire after period vs. before period, 2009 law change period vs. before period, corridor approach period vs. before period), study group indicator (Montgomery County vs. Fairfax County), road surface condition indicator (wet/snowy/icy vs. dry), road alignment indicator (curved vs. straight). In addition, speed limit indicators (30 vs. 25 mph, 35 vs. 25 mph) were included in the models of crashes on camera-eligible roads.

The logistic regression models also included three interaction variables for study group and study period indicators as the measures of the effects of the speed camera program, additional effects of the law change over and above the camera effect, and additional effects of the corridor approach over and above the camera effect and law change effect. From the estimated parameters for these interaction terms, the change in the likelihood that a crash was speeding-related beyond what would have been expected absent the speed cameras, the law change, or the corridor approach were calculated (Zhang and $\mathrm{Yu}, 1998)$.

Figure A-1 plots the percentage of crashes that were speeding related for each of the study years for the camera-eligible roads (roads with 25-35 mph speed limits) and for the potential spillover roads (roads with 40 mph speed limits) in Montgomery County and for the 
associated control roads in Fairfax County. The proportions of crashes that were speeding-related in Fairfax County were substantially higher in 2008 than in other years. The reason for this anomaly could not be identified but it may reflect a transition in coding methods in terms of how speeding-related crashes were identified. As a result, the data from 2008 were excluded from the analyses of the effects of speed cameras on speeding-related crashes.

There was a general downward trend in the yearly proportion of crashes that were speeding-related on camera-eligible roads in Montgomery County, on the corresponding control roads in Fairfax County, and on potential spillover roads in Montgomery County, whereas the proportion on the control roads in Fairfax County for potential spillover effects was relatively stable.

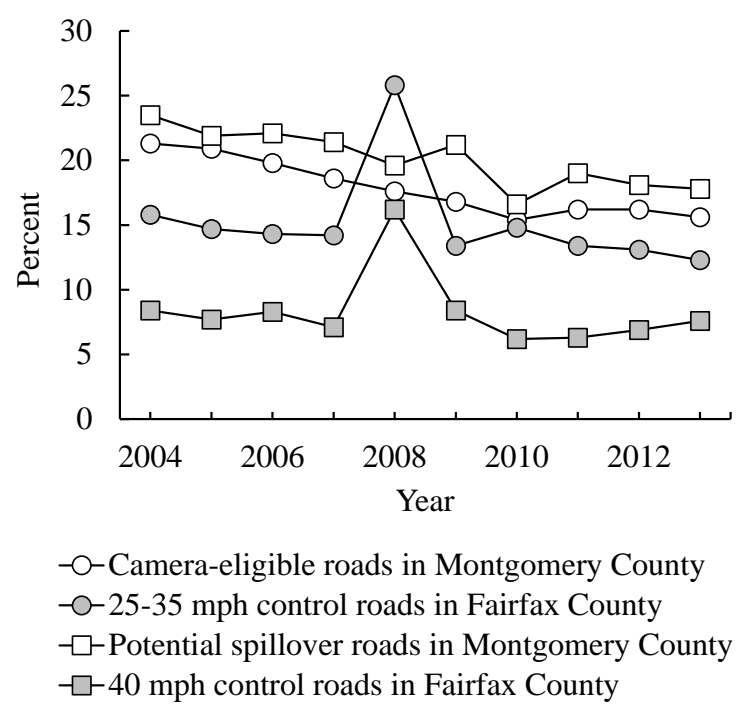

Fig. A-1. Percentage of police-reported crashes that were speeding-related during 2004-2013 by study group

The logistic regression estimated the effects of the camera program on the likelihood that a crash was speeding-related on camera-eligible roads and on potential spillover roads. 
Descriptive statistics of variables included in the models were provided in Table A-6. Estimated models are presented in Tables A-7 and A-8, respectively. 


\section{Table A-6}

Descriptive statistics of variables in the logistic regression models of the likelihood that crash was speeding-related on camera-eligible roads and on potential spillover roads

\begin{tabular}{|c|c|c|c|c|c|}
\hline \multirow{6}{*}{ Variables } & \multirow{6}{*}{ Description } & \multicolumn{2}{|c|}{ Model on } & \multicolumn{2}{|c|}{ Model on } \\
\hline & & \multicolumn{2}{|c|}{ camera } & \multicolumn{2}{|c|}{ potential } \\
\hline & & \multicolumn{2}{|c|}{ eligible } & \multicolumn{2}{|c|}{ spillover } \\
\hline & & \multicolumn{2}{|c|}{ roads } & \multicolumn{2}{|c|}{ roads } \\
\hline & & Mea & & Mea & Std \\
\hline & & $\mathrm{n}$ & dev & $\mathrm{n}$ & dev \\
\hline & & 0.16 & 0.001 & 0.16 & 0.002 \\
\hline Crash being speeding-related & 1 if a crash was speeding-related, 0 otherwise & & 1 & & 2 \\
\hline First quarter (Jan-Mar) vs. fourth quarter & & 0.24 & 0.001 & 0.23 & 0.002 \\
\hline (Oct-Dec) & 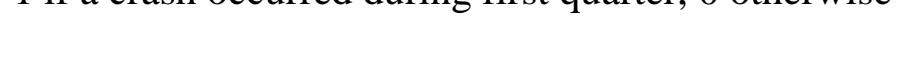 & & 2 & & 4 \\
\hline Second quarter (Apr-Jun) vs. fourth quarter & 1 if a crash occurred during second quarter, 0 & 0.24 & 0.001 & 0.24 & 0.002 \\
\hline (Oct-Dec) & otherwise & & 2 & & 5 \\
\hline
\end{tabular}


Third quarter (Jul-Sep) vs. fourth quarter

(Oct-Dec)

Entire after period (Jun 2007-Dec 2013) vs. 1 if a crash occurred during occurred during Jun 2007-

before period (Jan 2004-Apr 2007)

2009 law period (Oct 2009-Dec 2013) vs.

before period (Jan 2004-Apr 2007)

Corridor approach period (Jun 2012-Dec

2013) vs. before period (Jan 2004-Apr

2007)

Montgomery County vs. Fairfax County

Wet/snowy/icy road vs. dry road

Curve road vs. straight road
1 if a crash occurred during third quarter, 0 otherwise Dec 2013, 0 otherwise

1 if a crash occurred during occurred during Oct

2009-Dec 2013, 0 otherwise

1 if a crash occurred during occurred during Jun 2012-

Dec 2013, 0 otherwise

1 if a crash occurred in Montgomery County,

0 if in Fairfax County

1 if a crash occurred on wet/ snowy/icy road,

0 if on dry road

1 if a crash occurred on a curve, 0 if on straight road $\begin{array}{llll}0.24 & 0.001 & 0.25 & 0.002\end{array}$

2

5

$\begin{array}{llll}0.56 & 0.001 & 0.59 & 0.002\end{array}$

4

8

$\begin{array}{llll}0.41 & 0.001 & 0.43 & 0.002\end{array}$

4

9

$0.15 \quad 0.001$

$0.16 \quad 0.002$

0

1

$\begin{array}{llll}0.44 & 0.001 & 0.68 & 0.002\end{array}$

4

7

$\begin{array}{llll}0.23 & 0.001 & 0.24 & 0.002\end{array}$

2

5

$\begin{array}{llll}0.14 & 0.001 & 0.10 & 0.001\end{array}$

0 
Nighttime (9 p.m. to 6 a.m.) vs. daytime

Speed limit $30 \mathrm{mph}$ vs. $25 \mathrm{mph}$

Speed limit 35 mph vs. 25 mph
1 if a crash occurred during nighttime, 0 otherwise

1 if a crash occurred on a road with $30 \mathrm{mph}$ speed

limit, $\quad 0$ otherwise

1 if a crash occurred on a road with $35 \mathrm{mph}$ speed

limit, $\quad 0$ otherwise $\begin{array}{llll}0.17 & 0.001 & 0.16 & 0.002\end{array}$

1

1

$0.16 \quad 0.001$

0

$0.56 \quad 0.001$

4 


\section{Table A-7}

Logistic regression results of effects of speed cameras on likelihood that crash was speedingrelated on camera-eligible roads

\begin{tabular}{|c|c|c|c|}
\hline \multirow[b]{2}{*}{ Parameter } & \multicolumn{3}{|c|}{ Standard } \\
\hline & Estimate & error & p-value \\
\hline Intercept & -2.1981 & 0.0288 & $<0.0001$ \\
\hline Number of years (since 2004) & -0.0229 & 0.01 & 0.0228 \\
\hline First quarter (Jan-Mar) vs. fourth quarter (Oct-Dec) & 0.00338 & 0.025 & 0.8923 \\
\hline Second quarter (Apr-Jun) vs. fourth quarter (Oct- & 0.0158 & 0.0241 & 0.5135 \\
\hline \multicolumn{4}{|l|}{ Dec) } \\
\hline Third quarter (Jul-Sep) vs. fourth quarter (Oct-Dec) & 0.071 & 0.0239 & 0.0029 \\
\hline Entire after period (Jun 2007-Dec 2013) vs. before & -0.0205 & 0.0469 & 0.6615 \\
\hline \multicolumn{4}{|l|}{ period (Jan 2004-Apr 2007) } \\
\hline 2009 law period (Oct 2009-Dec 2013) vs. before & 0.0303 & 0.0467 & 0.5165 \\
\hline \multicolumn{4}{|l|}{ period (Jan 2004-Apr 2007) } \\
\hline Corridor approach period (Jun 2012-Dec 2013) vs. & -0.0227 & 0.0444 & 0.6087 \\
\hline \multicolumn{4}{|l|}{ before period (Jan 2004-Apr 2007) } \\
\hline Montgomery County vs. Fairfax County & 0.3467 & 0.0252 & $<0.0001$ \\
\hline Effects of speed cameras & -0.1529 & 0.0508 & 0.0026 \\
\hline Effects of 2009 law change over and above speed & -0.0409 & 0.0556 & 0.462 \\
\hline \multicolumn{4}{|l|}{ cameras } \\
\hline Effects of corridor approach over and above speed & 0.0911 & 0.056 & 0.1037 \\
\hline
\end{tabular}


Wet/snowy/icy road vs. dry road

$0.8903 \quad 0.018<0.0001$

Curve road vs. straight road

$1.0215 \quad 0.02 \quad<0.0001$

Nighttime (9 p.m. to 6 a.m.) vs. daytime

$0.864 \quad 0.0197<0.0001$

Speed limit $30 \mathrm{mph}$ vs. $25 \mathrm{mph}$

$-0.1881<0.0264<0.0001$

Speed limit 35 mph vs. $25 \mathrm{mph}$

$-0.21$

$0.0194<0.0001$

Note: p-value was based on Wald Chi-Square test.

\section{Table A-8}

Logistic regression results of effects of speed cameras on likelihood that crash was speedingrelated on potential spillover roads

Standard

Parameter

Estimate error p-value

Intercept

$-3.0923 \quad 0.0739<0.0001$

Number of years (since 2004)

$\begin{array}{lll}0.0229 & 0.0201 & 0.2544\end{array}$

First quarter (Jan-Mar) vs. fourth quarter (Oct-Dec)

$\begin{array}{lll}0.0103 & 0.05 & 0.8366\end{array}$

Second quarter (Apr-Jun) vs. fourth quarter (Oct-

$\begin{array}{lll}-0.0547 & 0.0487 & 0.2613\end{array}$

Dec)

Third quarter (Jul-Sep) vs. fourth quarter (Oct-Dec)

$0.0592 \quad 0.0475 \quad 0.2125$

Entire after period (Jun 2007-Dec 2013) vs. before

$0.0331 \quad 0.1344 \quad 0.8055$

period (Jan 2004-Apr 2007)

2009 law period (Oct 2009-Dec 2013) vs. before

$\begin{array}{lll}-0.4123 & 0.1407 & 0.0034\end{array}$

period (Jan 2004-Apr 2007) 
Corridor approach period (Jun 2012-Dec 2013) vs.

0.2399

0.1379

0.0819

before period (Jan 2004-Apr 2007)

Montgomery County vs. Fairfax County

$1.1357 \quad 0.0694<0.0001$

Effects of speed cameras

$-0.2146$

0.1314

0.1024

Effects of 2009 law change over and above speed

0.226

0.1447

0.1182

cameras

Effects of corridor approach over and above speed

$-0.2789$

0.1447

0.0539 cameras and 2009 law change

Wet/snowy/icy road vs. dry road

1.375

$0.0347<0.0001$

Curve road vs. straight road

1.0176

$0.0462<0.0001$

Nighttime (9 p.m. to 6 a.m.) vs. daytime

$0.3638 \quad 0.0424<0.0001$

Note: p-value was based on Wald Chi-Square test.

After adjusting for yearly and quarterly trends, time of day, speed limits, road surface condition, road alignment, and study group (Montgomery County vs. Fairfax County), the estimated effects of the speed cameras, 2009 law change, and corridor approach are summarized in Table A-9. For crashes that occurred on camera-eligible roads, based on the interaction term between study group and the entire after period vs. before period, the likelihood of a crash being speeding-related was an estimated $12.3 \%$ lower than would have been expected without speed cameras, a significant difference. The estimated effect of the law change in addition to the effect of speed cameras was a non-significant 3.4\% decline from what would have been expected without the law change. The likelihood of a crash being speeding-related was an estimated 8\% higher than would have been expected without the corridor approach, a difference that was not 
significant. Based on the combined effects of the speed cameras, law change, and corridor approach, the likelihood that a crash was speeding-related was $8.4 \%$ lower than would have been expected without any of the treatments, and this difference was significant.

Similarly, for crashes that occurred on potential spillover roads, the likelihood of a crash being speeding-related was an estimated $18 \%$ lower than would have been expected without the speed cameras, an additional 22.9\% higher than would have been expected without the law change, and an additional 22.8\% lower than would have been expected without the corridor approach. None of these differences was significant, although the difference for the corridor approach neared significance. Based on the combined effects of the speed cameras, 2009 law change, and corridor approach, the likelihood that a crash was speeding-related on potential spillover roads was $22 \%$ lower than would have been expected without any of the treatments, and this difference was significant.

\section{Table A-9}

Summary of results from logistic regression models of percentage changes in the likelihood that crash was speeding-related associated with use of speed cameras on camera-eligible roads and on potential spillover roads

\begin{tabular}{|c|c|}
\hline 25-35 mph camera-eligible & $40 \mathrm{mph}$ potential spillover \\
\hline roads & roads \\
\hline Percent change & Percent change \\
\hline in likelihood & in likelihood \\
\hline that crash was & that crash was \\
\hline speeding-related p-value & speeding-related p-value \\
\hline
\end{tabular}




\begin{tabular}{lcccc}
\hline Effects of speed cameras & -12.3 & 0.0026 & -18.0 & 0.1024 \\
Effects of 2009 law change over and & -3.4 & 0.462 & 22.9 & 0.1182 \\
above effects of speed cameras & & & & \\
$\begin{array}{l}\text { Effects of corridor approach over } \\
\text { and above effects of speed cameras }\end{array}$ & & & & \\
and 2009 law change & & & & \\
Combined effects of speed cameras, & -8.4 & 0.0539 & \\
2009 law change, and corridor & & & -22.0 & 0.0418 \\
approach & & & & \\
\hline
\end{tabular}

Note: Data from calendar year 2008 excluded. 